\title{
Extracellular polymeric substances with high radical scavenging ability produced in outdoor cultivation of the thermotolerant chlorophyte Graesiella sp.
}

\author{
Wejdene Gongi $^{1,2} \cdot$ Nereida Cordeiro ${ }^{3,4} \cdot$ Juan Luis Gomez Pinchetti ${ }^{5} \cdot$ Saloua Sadok $^{1} \cdot$ Hatem Ben Ouada $^{1}$
}

Received: 16 June 2020 / Revised and accepted: 12 October 2020

(C) Springer Nature B.V. 2020

\begin{abstract}
The present study developed a two-step strategy to enhance the production of extracellular polymeric substances (EPSs) by a thermotolerant chlorophyte, Graesiella sp., in view to their industrial valorisation. In the first step, Graesiella sp. was grown in outdoor conditions in pilot-scale photobioreactors of $100 \mathrm{~L}$ culture volumes. In the second step, the biomass collected in the exponential growth phase was submitted to heat stress $\left(50^{\circ} \mathrm{C}\right)$. A joint production of biomass reaching $0.50 \mathrm{~g}_{\mathrm{dw}} \mathrm{L}^{-1} \mathrm{day}^{-1}$ and of EPS production reaching $1.30 \mathrm{~g}_{\mathrm{dw}} \mathrm{L}^{-1}$ in 2 days was obtained. EPSs mainly contained polysaccharides (80\%) and proteins (14\%). FTIR and ${ }^{1}$ HNMR revealed the presence of primary amine and sulfated groups. The EPSs contained antioxidant enzymes (SOD, CAT, and APX) maintained in an active state by the microenvironment offered by the EPSs. The EPSs were found to have a potent antioxidant activity via directly scavenging free radicals when compared to L-ascorbic acid.
\end{abstract}

Keywords Microalgae $\cdot$ Graesiella $\cdot$ Chlorophyta $\cdot$ EPSs · Antioxidant enzymes · Characterization · Radical scavenging · Outdoor cultivation · Two-step strategy

\section{Introduction}

In various sectors such as food, cosmetic, and health, the market is growing rapidly in the support of the development of "bio" products and in a global context of demand for reduction of chemical additives. Recently, it has been shown that the microalgae field has significant potential (Vigani et al. 2015) supporting the transition from a fossil fuel-based economy and the global mass-market industry to a "circular

Hatem Ben Ouada

hatbenouada@gmail.com

1 Laboratory of Blue Biotechnology \& Aquatic Bioproducts, National Institute of Marine Sciences and Technologies, 5000 Monastir, Tunisia

2 National Institute of Agronomy, University of Carthage, 1082 Tunis, Tunisia

3 LB3 Faculty of Science and Engineering, University of Madeira, 9000-390 Funchal, Portugal

4 CIIMAR, Interdisciplinary Centre of Marine and Environmental Research, University of Porto, 4450-208 Matosinhos, Portugal

5 Spanish Bank of Algae, Institute of Oceanography and Global Change (IOCAG), University of Las Palmas de G.C, Muelle de Taliarte s/n, 35214 Telde, Canary Islands, Spain bioeconomy" responding to a growing demand of civil society. Although the total production volumes and market size of products derived from microalgae increased 5-fold since the beginning of the century, they are still relatively small and little diversified with respect to alternative sources (Enzing et al. 2014). In this context, the mobilization of new microalgal resources with the versatility of applications (human and animal food and bioactives) would make original contributions to improve the potential of microalgae as a future source of renewable bioproducts.

Among these resources, thermotolerant microalgae strains have exceptional potential. Several authors have found that these microalgae strains, with high optimal growth temperature, have higher productivity (Bleeke et al. 2015; Xiao and Zheng 2016), especially in summer outdoor climatic conditions where high temperatures often result in an inhibition of the growth of common microalgae species. Furthermore, as a consequence of growth at high temperatures, thermotolerant microalgae can possess wide possibilities for physiological adaptation and genetic modifications that make them potential producers of high-value thermo-stable bioactive compounds (Haki and Rakshit 2003).

Almost all of today's industrial microalgae products of interest are derived from their intracellular biomass. However, microalgae can also release various extracellular polymeric 
substances (EPSs) into the medium (Xiao and Zheng 2016; Ekelhof and Melkonian 2017; Gaignard et al. 2018) a resource which is still largely untapped. They can be the key solution for the effective economic sustainability of the microalgae industry.

Extracellular polymeric substances (EPSs), also called exopolysaccharides, represent a class of valuable polymers. The common EPSs of most microalgae are of heterosulfated polysaccharidic nature, containing a large amount of carbohydrates in addition to proteins, fats, nucleic acids, and inorganic substituents (Rossi and De Philippis 2016; Halaj et al. 2018). Thermotolerant microalgae species have developed specific extracellular polymeric substances that make the cell grow and flourish under extreme temperature conditions (Mezhoud et al. 2014; Varshney et al. 2015) but real strategies to their industrial production have scarcely been studied.

EPSs are currently used as emulsifier, thickener, flocculent, and gelling agents (Mishra et al. 2011; Han et al. 2014). Certain microalgal EPSs are reported to possess diverse biological activities including anti-inflammatory (Bae et al. 2006), immunomodulatory (Guzmán et al. 2003), antitumor (Raposo et al. 2014), antiviral (Huheihel et al. 2002), antifungal, and antibacterial (Abedin and Taha 2008) activities.

Antioxidant and reactive oxygen species (ROS) scavenging properties of EPSs have been also reported in several microalgal species (Bkhairia et al. 2016; Zhang et al. 2019a, b), although, rarer than those reported from filamentous fungi (Lin et al. 2012) and bacteria (Li et al. 2013). In general, the antioxidant activity of microalga EPSs is attributed to their polysaccharidic fraction or inorganic substituents as sulfated groups (Tannin-Spitz et al. 2005; Sun et al. 2014). Protein fractions in EPSs are also implied in the antioxidant activity of several microalgae/cyanobacteria species (Gao et al. 2015). The ROS-scavenging role of EPSs produced by Microcystis aeruginosa was attributed to the water-soluble protein MAAs (mycosporine-like amino acids) (Hu et al. 2015).

Reactive oxygen species (ROS) and oxygen-derived free radicals produced in all vital organisms are very dangerous and contribute to pathological effects and many illnesses, including DNA damage, cellular degeneration, Alzheimer's, cancer, liver injury, and heart diseases (Gioti et al. 2007; Valko et al. 2007). Currently, synthetic antioxidants such as propylgallate, butylated hydroxytoluene, and butylated hydroxyanisole are used in order to reduce damage (Gülçin 2006) but they are suspected to be responsible of liver damage and carcinogenesis (Orčić et al. 2011). Therefore, the search for natural resources as potential and safe antioxidants is becoming important (Li et al. 2007).

Given the above considerations, the purpose of this study was to increase the production of EPSs from the thermotolerant chlorophyte strain Graesiella sp., isolated from Tunisian geothermal waters and in the perspective of industrial valorization. In view to make results more useful for industrial extrapolation, the experimental cultures were grown at pre-pilot scale (100 L culture volume) and in outdoor conditions. A two-step strategy was employed to enhance EPS production. Furthermore, the obtained EPSs were characterized using chromatographic and spectrophotometric methods, and EPSs antioxidant activity (total antioxidant, $\alpha, \alpha$ diphenyl- $\beta$-picrylhydrazyl radical scavenging, iron-reducing power, hydroxyl radical scavenging, and hydrogen peroxide radical scavenging) was studied. Due to their high importance, the presence of antioxidant enzymes in the EPSs received particular attention.

\section{Materials and methods}

\section{Algal strain and culture medium}

A thermophilic green algal strain identified by phylogenetic analysis as Graesiella sp. (Mezhoud et al. 2014) isolated from microbial mats anchored to submerged stones, in a hot spring (Ain Echffa) located in the northern part of Tunisia $\left(36^{\circ} 49^{\prime} \mathrm{N}\right.$, $10^{\circ} 34^{\prime} \mathrm{E}$ ) at a water temperature of $60^{\circ} \mathrm{C}$ was used. The Graesiella strain (axenic colonies) was cultivated in batch culture under sterile conditions in Bold's Basal Medium (BBM) (Bischoff and Bold 1963) modified according to the Elser concept for freshwater microalgae, with C:N:P ratio equal to 166:20:1 (Tang and Dam 1999). The strain was grown preliminarily in laboratory under optimal growth conditions at $30 \pm 1{ }^{\circ} \mathrm{C}$ and $120 \mu \mathrm{mol}$ photons $\mathrm{m}^{-2} \mathrm{~s}^{-1}$ as suggested by Mezhoud et al. (2014). The increase in the culture volume up to $20 \mathrm{~L}$ was carried out gradually by weekly subcultures in Erlenmeyer flasks.

\section{Experimental cultures}

To enhance the EPS production, Graesiella sp. was subjected a two-step strategy: step I: the growth step (9 days), where the alga was grown in outdoor conditions; and step II: the stress step, where the concentrated biomass provided from step I, was subjected to temperature stress conditions for 2 days, after total medium renewal.

\section{Growth step—step I}

In this initial step, growth was achieved outdoor under August environmental conditions at the facilities of the Spanish Bank of Algae (BEA), Gran Canaria (Canary Islands). Cultures were grown in enclosed cylindrical photobioreactors consisting on glass columns $(20 \mathrm{~cm} \times 110 \mathrm{~cm}=$ diameter $\times$ height) and $108 \mathrm{~L}$ volume each and exposed for 9 days to natural light and temperature conditions. The pre-cultures (see the "Chlorophyta strain and culture medium" section) in the stationary phase were used to inoculate $\left(B_{t}\right.$ of 
$\left.0.08 \mathrm{~g}_{\mathrm{dw}} \mathrm{L}^{-1}\right) 100 \mathrm{~L}$ culture volumes. The temperature in the water culture was between 30 and $35{ }^{\circ} \mathrm{C}$, during the whole experimental period. Aeration was supplied $24 \mathrm{~h}$ on the day by an air compressor at a flow rate of $1.5 \mathrm{~L} \mathrm{~min}^{-1}$.

\section{Stress step-step II}

In this step, the algal biomass harvested at the end of the exponential growth phase-step I by centrifugation $\left(3985 \times g, 10\right.$ min at $4{ }^{\circ} \mathrm{C}$ ) was washed with fresh BBM medium, centrifuged again, and re-suspended in $5 \mathrm{~L}$ flat glass flasks, at biomass density of $2 \mathrm{~g}_{\mathrm{dw}} \mathrm{L}^{-1}$. EPSs induction was ensured by submitting the concentrated biomass to thermal stress for 2 days. Stressed cultures were placed in thermostat chamber (BOECO Orbital Shaker Incubator ES-20/80) at 50 $\pm 1{ }^{\circ} \mathrm{C}$ and $120 \mu \mathrm{mol}$ photons $\mathrm{m}^{-2} \mathrm{~s}^{-1}$.

\section{Determination of biomass growth and EPS production}

The algal cell growth was monitored by the daily $(t)$ changes in the biomass density. The biomass density $\left(\mathrm{g}_{\mathrm{dw}} \mathrm{L}^{-1}\right)$ was determined gravimetrically by measuring daily dry weight. Samples $(1 \mathrm{~L})$, in triplicate, were filtered over prewashed $0.2 \mu \mathrm{m}$ microfiber filters (GF/F filter, Whatman, UK) and dried overnight at $80{ }^{\circ} \mathrm{C}$. The filters were cooled to room temperature in a desiccator prior to weighing.

The EPSs were extracted from the Graesiella cultures by stirring the culture for $30 \mathrm{~min}$, followed by centrifugation (3985 $\times \mathrm{g}$ for $10 \mathrm{~min}$, at $4{ }^{\circ} \mathrm{C}$ ), to separate the algal cells from the culture medium containing the released EPSs. The biomass was washed with deionized water and centrifuged. The total recovered supernatant (culture medium and soluble EPS) was concentrated (10 times) by tangential ultrafiltration (Vivaflow 50) with Millipore membranes with a cut-off of $8 \mathrm{kDa}$. The elimination of low molecular weight substances and inorganics was ensured by a cycle of consecutive concentrations and dilutions with ultrapure water until constant conductivity $\left(0.017 \mathrm{mS}^{-1}\right)$. The recovered filtrate rich in EPS was freeze-dried and weighed for gravimetric EPS content determination.

The biomass and EPS productivities $\left(P ; \mathrm{g}_{\mathrm{dw}} \mathrm{L}^{-1}\right.$ day $\left.^{-1}\right)$ at any culture time $(t)$ were calculated from Eq. 1 with $C_{0}$ and $C_{\mathrm{t}}$ as the dry mass density $\left(g_{\mathrm{dw}} \mathrm{L}^{-1}\right)$ at start and time $t$ (day), respectively.

$P t=\frac{C_{\mathrm{t}}-C_{0}}{t}$

\section{Biochemical characterization}

The carbohydrate content in the EPSs was determined by the phenolsulfuric acid method according to Dubois et al. (1956).
In this method, the sugars in the EPSs are hydrolyzed by concentrated sulfuric acid during the phenol-sulfuric assay and form monomers, namely glucose, fructose, and galactose. The carbohydrate concentration was obtained using a calibration curve of glucose (99.5\%, Sigma-Aldrich, G8270) and the absorption was recorded at $490 \mathrm{~nm}$. Protein content was determined according to Lowry et al. (1951) using bovine serum albumin (98\%, Sigma-Aldrich, B2064) as standard. Lipid amount was determined using the method of Folch et al. (1957). The elemental analysis (C, N, H, S, and P) of samples was conducted using a Flash Elemental Analyzer 1112. The results were expressed in \% relative to the EPS dry weight $\left(d_{\mathrm{w}}\right)$.

\section{Fourier transformed infrared spectroscopy analysis}

Fourier transformed infrared (FTIR) spectra of the EPSs were recorded in the region of $3900-800 \mathrm{~cm}^{-1}$ by grinding in $\mathrm{KBr}$ disks, followed by pressing into a $16 \mathrm{~mm}$-diameter mold with a Perkin-Elmer spectrum GX FTIR system (Perkin-Elmer, USA). The spectrum was evaluated by the Agilent software.

\section{Proton nuclear magnetic resonance spectroscopy analysis}

Proton nuclear magnetic resonance $\left({ }^{1} \mathrm{HNMR}\right)$ spectroscopy of the EPSs was achieved on Bruker ASX400-WB spectrometer equipped with a double resonance $(1 \mathrm{H} / \mathrm{X})$ Broad Band Inverse z-gradient probe head. Samples were exchanged in $25 \mu \mathrm{L}$ deuterated water $\left(\mathrm{D}_{2} \mathrm{O}\right)$ with intermediate freeze-drying. Chemical shifts were expressed in ppm downfield from the signal of the methyl group of internal acetone $\left(\delta^{1} \mathrm{H}^{1 / 4}\right.$ $2.225 \mathrm{ppm}$ at $300 \mathrm{~K}$ ). The samples were analyzed in $5 \mathrm{~mm}$ susceptibility matched tubes (Shigemi, Japan). Integration of spectra and data analyses was performed with MESTRENOVA (version 2016).

\section{X-ray diffractometry analysis}

X-ray diffraction analysis of the crude EPSs was performed with an X-ray diffractometer CICECO Empyrean (JDX 3532; Japan). The diffraction angle range of observation was 5 to $60^{\circ}$, with a scan step of 0.02 .

\section{High performance liquid chromatography analysis}

The high performance liquid chromatography (HPLC) apparatus used for the experiments was an Agilent Technologies HP 1200 series system, equipped with two preparative pumps (G1361A), a degasser, an injection valve with a $20 \mu \mathrm{L}$ and $5 \mathrm{~mL}$ loops, an autosampler (DLA G2258A), a diode array multiple wavelength detector SL (G 1315D), and an Alltech conductivity detector model 650 . A volume injection of $1 \mathrm{~mL}$ of water-soluble EPSs filtered through $2 \mu \mathrm{m}$ syringe filter was 
analyzed by reverse-phase HPLC. The analytical column used was an Agilent PL Aquagel $\mathrm{OH} 50$ column $(300 \mathrm{~mm} \times$ $10 \mathrm{~mm} \times 8 \mu \mathrm{m}$ ). The identification of compounds was based on the retention time, the UV visible spectra, and the conductivity. All samples were injected via a DLA G2258A autosampler provided with a $5 \mathrm{~mL}$ syringe. The EPS compounds were separated in isocratic conditions, using deionized water as mobile phase and detected at $246 \mathrm{~nm}$. The flow rate

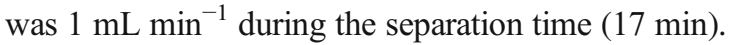

\section{Electrophoresis profile}

Enzymatic hydrolysis of the EPSs $\left(20 \mathrm{mg}_{\mathrm{dw}} \mathrm{mL}^{-1}\right)$ was performed using $0.05 \%$ Protamex (Novozymes A/S, Denmark, produced by Bacillus protease, containing both enzymes Neutrase and Alcalase). The mixture (enzyme + EPS solutions) was stirred continuously with a propeller in a water bath at $50{ }^{\circ} \mathrm{C}$ for $180 \mathrm{~min}$. The $\mathrm{pH}$ was adjusted and kept at 8.0 by adding $1 \mathrm{M} \mathrm{NaOH}$ during the reaction (Córdova-Murueta et al. 2003). After that, the mixture was heated at $100{ }^{\circ} \mathrm{C}$ for $5 \mathrm{~min}$ and cooled to room temperature in order to stop the proteolysis. The obtained solution was centrifuged for $30 \mathrm{~min}$ at $5000 \times \mathrm{g}$ and at $4{ }^{\circ} \mathrm{C}$ to obtain EPS protein hydrolysate.

Subunit components of the obtained EPS protein hydrolysate were analyzed using sodium dodecyl sulfatepolyacrylamide gel (SDS-PAGE). Electrophoresis analysis was carried out in a vertical chamber using $12 \%$ polyacrylamide gel with sodium dodecyl sulfate (Laemmli 1970). Samples $(20 \mu \mathrm{L})$ of the EPS hydrolysate were boiled for 15 min at $100{ }^{\circ} \mathrm{C}$ in $5 \mu \mathrm{L}$ of sample buffer containing $0.5 \mathrm{mM}$ Tris- $\mathrm{HCl}, \mathrm{pH} 6.8,25 \%$ glycerol, $1 \%$ bromophenol blue, $10 \%$ SDS, and 3\% $\beta$-mercaptoethanol (added immediately before use). The molecular protein weight marker used was electrophoresis marker mol wt 10-200 kDa obtained from Sigma-Aldrich (mPAGE Unstained Protein Standard, SDS7B2). The SDS-PAGE was carried out with a constant current of 1-2 mA per track for 2-3 h. After electrophoresis, the gel was stained with Coomassie Blue overnight and the discoloration of the gel was made up with solution containing $40 \%$ ultrapure water, $40 \%$ methanol, and $10 \%$ acetic acid. Images of the gel were analyzed by the Software Gel Analyzer.

\section{Antioxidant enzymes assays}

The EPSs were used for the determination of enzymatic antioxidant superoxide dismutase (SOD), catalase (CAT), and ascorbate peroxidase (APX). A spectrophotometric quantification was used for the above-mentioned assays using a Beckman coulter DU 640B spectrophotometer. All the determinations were made in triplicate at ambient temperature. Enzymatic activities were expressed as unit per mg of protein. One unit is defined as the quantity of enzymes that catalyze the conversion of $1 \mu \mathrm{mol}$ of substrate per min. Standard curves for all enzymes analysis were obtained at $4{ }^{\circ} \mathrm{C}$ using enzymatic assays kits (Merck Sigma-Aldrich).

CAT activity was determined following the decomposition of hydrogen peroxide $\left(\mathrm{H}_{2} \mathrm{O}_{2}\right)$ spectrophotometrically at $240 \mathrm{~nm}$, in a reaction mixture containing $50 \mathrm{mM} \mathrm{H}_{2} \mathrm{O}_{2}$ in $50 \mathrm{mM}$ potassium phosphate buffer (pH 7) (Aebi 1984). APX activity was determined according to Simonetti et al. (2010), following the decrease in absorbance at $290 \mathrm{~nm}$, of a reaction mixture containing $50 \mathrm{mM}$ potassium phosphate buffer ( $\mathrm{pH} 7$ ), $0.5 \mathrm{mM}$ ascorbate, $0.1 \mathrm{mM}$ EDTA, and $0.1 \mathrm{mM} \mathrm{H}_{2} \mathrm{O}_{2}$. SOD activity was performed by using an EnzyChrom Superoxide Dismutase Assay Kit (ESOD-100). SOD activity was determined by calculating the difference between the absorbance at $0 \mathrm{~min}$ and $1 \mathrm{~h}$, at wavelength of $440 \mathrm{~nm}$. The obtained results were compared to the different concentrations of SOD in the ESOD-100 kit.

\section{Antioxidant activity}

Total antioxidant capacity Total antioxidant capacity (TAC) was studied by the reduction of the green phosphomolybdenum complex according to Prieto et al. (1999). TAC was evaluated by the reduction of Mo (VI) to Mo (V) and measured by the absorbance at $695 \mathrm{~nm}$. Briefly, $100 \mu \mathrm{L}$ of EPS water solution (concentrations ranged from 20 to $2000 \mu \mathrm{g}_{\mathrm{dw}} \mathrm{mL}^{-1}$ ) was added to $1 \mathrm{~mL}$ of a reagent mixture and incubated for $1 \mathrm{~h}$ at $95{ }^{\circ} \mathrm{C}$. The reagent mixture solution consisting of $0.588 \mathrm{~mL}$ sulfuric acid, $0.049 \mathrm{~g}$ ammonium molybdate, and $0.036 \mathrm{~g}$ sodium phosphate made up to $10 \mathrm{~mL}$ with distilled water. The absorbance at $695 \mathrm{~nm}$ was used to evaluate the variation of the total antioxidant capacity. L-Ascorbic acid solution was prepared in the same conditions and was used as a standard (positive control).

a, $a$-Diphenyl- $\beta$-picrylhydrazyl radical scavenging activity The $\alpha, \alpha$-diphenyl- $\beta$-picrylhydrazyl (DPPH) radical scavenging activity was evaluated according to the method described by Shimada et al. (1992) with slight modifications. The EPS solutions (concentrations ranged from 20 to $2000 \mu \mathrm{g}_{\mathrm{dw}} \mathrm{mL}^{-1}$ ) were mixed with $500 \mu \mathrm{L}$ of a methanolic solution containing $\mathrm{DPPH}^{*}(0.02 \%)$. The mixture was then incubated for $1 \mathrm{~h}$ in the dark, at room temperature. A control solution containing DPPH $^{*}$ without EPSs was also prepared. The absorbance was measured at $517 \mathrm{~nm}$ and normalized to the $\mathrm{DPPH}^{\circ}$ control solution. The same procedure was made with $\mathrm{L}$-ascorbic acid as a standard. The scavenging activity of $\mathrm{DPPH}^{*}(\%)$ was determined using the Eq. 2 where $A_{\text {sample }}$ is the absorbance of the sample solution and $A_{\text {control }}$ is the absorbance of the sample control solution. The $\mathrm{IC}_{50}$, defined as the 
concentration of sample that scavenged $50 \%$ of $\mathrm{DPPH}^{\circ}$ radical, was determined.

$\%=\frac{A_{\text {control }}-A_{\text {sample }}}{A \text { control }} \times 100$

Iron-reducing power The method developed by Adjimani and Asare (2015) was used for testing the iron-reducing power. The EPS solutions (concentrations ranged from 20 to $2000 \mu \mathrm{g}_{\mathrm{dw}} \mathrm{mL}^{-1}$ ) or distilled water (control) were mixed separately with $0.5 \mathrm{~mL}$ of sodium phosphate buffer $(0.02 \mathrm{M}$, $\mathrm{pH} 7)$ and $2.5 \mathrm{~mL}$ of potassium ferricyanide $(1 \%, w / v)$. The mixture was then incubated for $30 \mathrm{~min}$ in a $50{ }^{\circ} \mathrm{C}$ water bath. After cooled, the resulting solution was mixed with $1.5 \mathrm{~mL}$ of $10 \%$ trichloroacetic acid and centrifuged $(800 \times g$ for $10 \mathrm{~min})$. The supernatant $(2 \mathrm{~mL})$ was then mixed with $0.5 \mathrm{~mL}$ of ferric chloride $(0.1 \%, \mathrm{w} / \mathrm{v})$. After allowing the reaction to proceed for $10 \mathrm{~min}$, the absorbance at $700 \mathrm{~nm}$ was measured. The scavenging activity (\%) was calculated using the Eq. 2 . The same procedure was made with L-ascorbic acid as standard. The $\mathrm{IC}_{50}$ was also determined.

Hydroxyl radical scavenging activity The hydroxyl radical $\left({ }^{\circ} \mathrm{OH}\right)$ scavenging activity was evaluated according to Chandran et al. (2013) where the ${ }^{\circ} \mathrm{OH}$ oxidize the $\mathrm{Fe}^{2+}$ into $\mathrm{Fe}^{3+}$, which react with 1,10-phenanthroline to form a red compound $\left(1,10\right.$-phenanthroline- $\left.\mathrm{Fe}^{2+}\right)$ with a maximum absorbance at $536 \mathrm{~nm}$. The concentration of ${ }^{\circ} \mathrm{OH}$ was determined by the degree of decolorization of the reaction solution. The EPS solutions (concentrations ranged from 20 to $2000 \mu \mathrm{g}_{\mathrm{dw}} \mathrm{mL}^{-1}$ ) were mixed separately with 1,10 phenanthroline solution $\left(1.0 \mathrm{~mL}, 1.865 \mathrm{mmol} \mathrm{L}^{-1}\right)$ and centrifuged and the supernatant absorbance measured. The ${ }^{\circ} \mathrm{OH}$ scavenging activity (\%) was calculated using Eq. 2 . The same procedure was made with L-ascorbic acid as standard. The $\mathrm{IC}_{50}$ was also determined.

Hydrogen peroxide scavenging activity The hydrogen peroxide $\left(\mathrm{H}_{2} \mathrm{O}_{2}\right)$ scavenging ability was determined following the procedure of Ruch et al. (1989). The EPS solutions (concentrations ranged from 20 to $2000 \mu \mathrm{g}_{\mathrm{dw}} \mathrm{mL}^{-1}$ ) were dissolved in a solution of $\mathrm{H}_{2} \mathrm{O}_{2}(43 \mathrm{mM})$ mixed with phosphate buffer $(0.1 \mathrm{M}$, $\mathrm{pH}$ 7.4). The absorbance value of the reaction mixtures $\left(A_{230}\right.$ sample) was recorded at $230 \mathrm{~nm}$. Distilled water was used as a control solution $\left(A_{230}\right.$ control). The $\mathrm{H}_{2} \mathrm{O}_{2}$ inhibition (\%) was calculated using Eq. 2. The same procedure was made with Lascorbic acid as standard. The $\mathrm{IC}_{50}$ was also determined.

\section{Statistical analysis}

The results were expressed as means \pm standard deviation (SD) of three replicates. Statistical analysis of the data was carried out using the software SPSS Statistics 20 . Differences between treatments were assessed with Student's $t$ test and the $p$ values $<0.05$ were considered to be statistically significant.

\section{Results and discussion}

\section{Biomass and EPS production}

In this work, Graesiella sp. isolated from the Tunisian hot spring water was grown under controlled conditions in a large-scale outdoor photobioreactor of $100 \mathrm{~L}$ culture volume. Graesiella sp. biomass and EPS kinetics were evaluated by following the increase in biomass density and EPS concentration, of the batch cultures grown over 9 days under natural environmental conditions (Fig. 1). The biomass kinetics (Fig. 1a) showed a typical sigmoidal shape and the highest biomass density obtained was of $1.94 \pm 0.25 \mathrm{~g}_{\mathrm{dw}} \mathrm{L}^{-1}$. The highest biomass productivity was registered at day 2 of culture and reached $0.50 \pm 0.02 \mathrm{~g}_{\mathrm{dw}} \mathrm{L}^{-1}$ day $^{-1}$. These values are greatly higher than that obtained in optimized Graesiella laboratory culture conditions observed by Zili et al. (2017); $0.40 \pm$ $0.01 \mathrm{~g}_{\mathrm{dw}} \mathrm{L}^{-1}$ of maximal biomass density and $0.17 \pm$ $0.03 \mathrm{~g}_{\mathrm{dw}} \mathrm{L}^{-1} \mathrm{~d}^{-1}$ as maximal biomass productivity.

Relatively to the EPSs, the production kinetics (Fig. 1b) showed a different shape marked by a long lag phase (4 days). The highest productivity of EPSs $\left(0.38 \pm 0.02 \mathrm{~g}_{\mathrm{dw}} \mathrm{L}^{-1} \mathrm{~d}^{-1}\right)$ was recorded later, day 5 of the culture period, with a maximal concentration of $1.46 \pm 0.07 \mathrm{~g}_{\mathrm{dw}} \mathrm{L}^{-1}$ obtained at the end of the experimental culture period. These results are greatly higher than that obtained for Graesiella laboratory culture $\left(0.29 \mathrm{~g}_{\mathrm{dw}} \mathrm{L}^{-1}\right.$; Mezhoud et al. 2014). Comparing the daily EPS production kinetics to the biomass growth rate time course, it was clear that production of EPSs occurred when biomass growth was reduced. This confirms the role of EPSs in the defense response metabolism as shown in different types of microalgae stresses including thermal ones (Lupi et al. 1991). In most microalgae and cyanobacteria species, EPSs are produced during the stationary growth phase (Delattre et al. 2016). In some cases, EPS production occurred during all growth phases but increases during the stationary one (Fernandes et al. 1989; Lama et al. 1996). However, under specific starvation conditions, some strains such as Nostoc can produce more EPSs in the exponential growth phase (Mehta and Vaidya 1978; Gantar et al. 1995).

In the case where the maximum productivity of biomass and EPSs is in the opposite production phases, the use of the two-stage cultivation strategy is the solution to jointly and continuously ensure a maximized production of the algal biomass and the EPSs. This strategy has been commonly used in the production of several intracellular secondary metabolites 
Fig. 1 Daily Biomass (a) and EPSs (b) kinetics in growth phase (step 1) of Graesiella sp. Outdoor culture. Full lines: biomass density and EPS concentration. Dotted lines: Biomass and EPS productivities. Data are shown as mean $\pm \mathrm{SD}(n=3)$
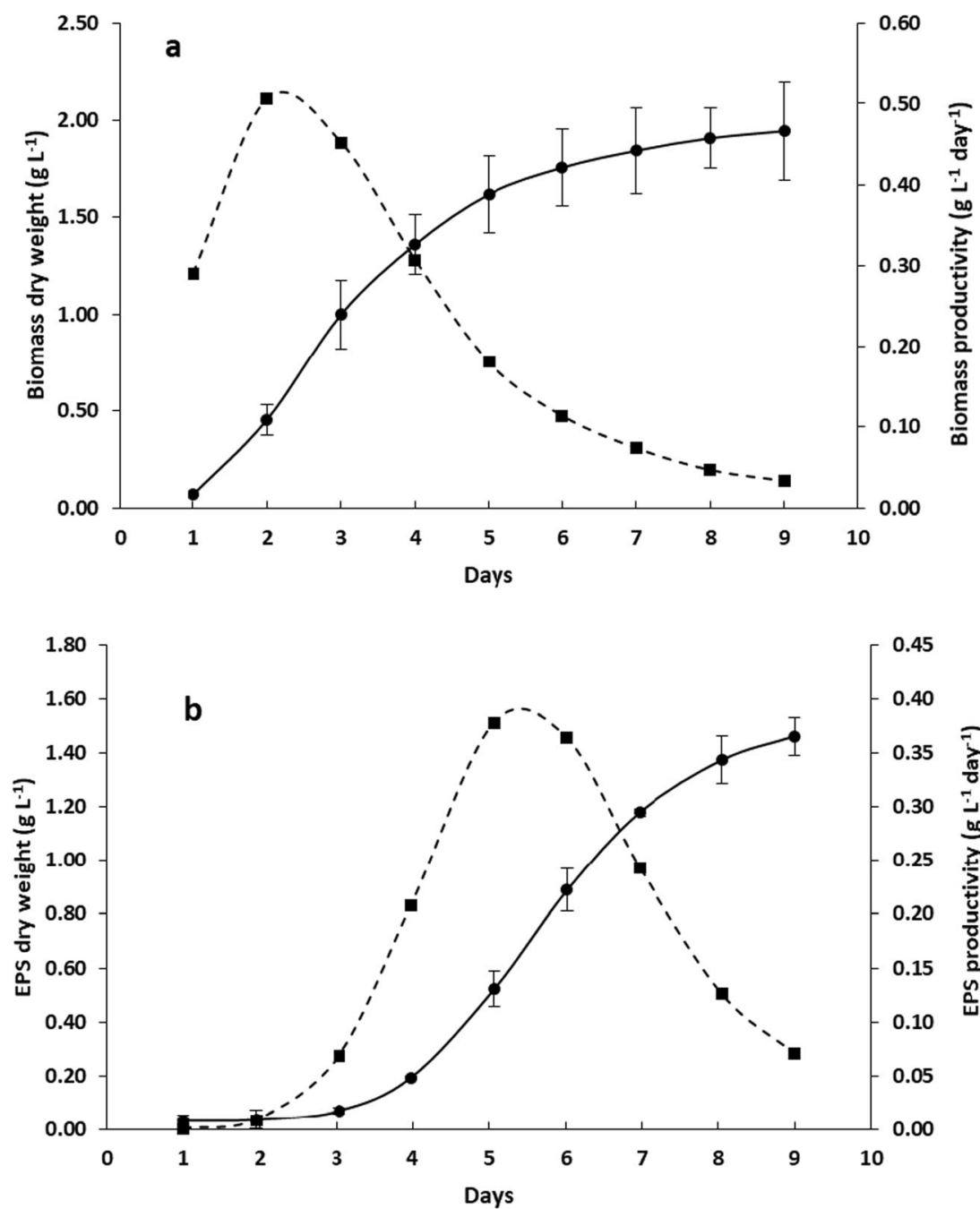

such as lipids and carotenoids (Hosseini and Shariati 2006; Zili et al. 2017) but rarely for EPSs.

Thus, Graesiella was subjected to a stress condition (step II) to enhance the EPS production. In this step, the biomass recovered at the end of the exponentially growth phase (day 2 of cultivation) was concentrated $\left(2 \mathrm{~g}_{\mathrm{dw}} \mathrm{L}^{-1}\right)$ and subjected to higher temperature $\left(50^{\circ} \mathrm{C}\right)$ in order to inhibit the growth, and thus, all the energy was oriented to the EPS synthesis. The EPS production greatly increased in 2 days, reaching $1.30 \mathrm{~g}_{\mathrm{dw}} \mathrm{L}^{-1}$. This value was slightly lower than that obtained at the end of step I of cultivation but 20-fold more than that recorded at the day 2 of maximum biomass productivity $\left(0.04 \mathrm{~g}_{\mathrm{dw}} \mathrm{L}^{-1}\right)$ representing an efficient way to ensure both high biomass yields and high EPS production.

The finding results emphasize that Graesiella $\mathrm{sp}$. is an efficient EPS producer. The EPS production commonly found in Chlorophyta species ranges from 0.38 (Halaj et al. 2018) to $0.94 \mathrm{~g}_{\mathrm{dw}} \mathrm{L}^{-1}$ (Mishra et al. 2011). Higher EPS rates to that recorded in this work have been reported for some algal strains such as Gyrodinium impudicum $\left(1.347 \mathrm{~g}_{\mathrm{dw}} \mathrm{L}^{-1}\right.$, Yim et al.
2004), Porphyridium marinum (2.5 $\mathrm{g}_{\mathrm{dw}} \mathrm{L}^{-1}$, Soanen et al. 2016), and Dictyosphaerium chlorelloides $\left(2.1 \mathrm{~g}_{\mathrm{dw}} \mathrm{L}^{-1}\right.$, Kumar et al. 2017).

\section{EPS biochemical characterization}

The EPSs were analyzed for carbohydrate, protein, lipid, and mineral contents (Table 1). High content of carbohydrates $(80.31 \%)$ with a relatively high amount of proteins $(14.10 \%)$ and the presence of lipids were detected. These results reveal the heteropolymeric nature of the extracted EPSs from Graesiella sp. The elementary analysis supports this observation with high levels of nitrogen $(12.3 \%)$, sulfur $(0.6 \%)$, and phosphorous $(0.5 \%)$. The total mineral components were less than $2 \%$, which shows that the extracted EPSs were mostly constituted of organic components, demonstrating that ultrafiltration system used was adequate for EPS purification.

The heteropolymeric nature detected in the Graesiella sp. EPSs has been found in most microalgae and Chlorophyta. Compositional analysis of EPSs includes frequently, in 
Table 1 Carbohydrates, protein, lipids, minerals, and elemental analysis composition (\% in EPS dry weight) of the EPSs produced by Graesiella sp. Values are given in mean of three replicates \pm SD

\begin{tabular}{lllllllll}
\hline Carbohydrates & Proteins & Lipids & Minerals & & \multicolumn{2}{l}{ Elemental composition } & \\
\cline { 5 - 9 } & & & & $\mathrm{C}$ & $\mathrm{N}$ & $\mathrm{H}$ & $\mathrm{S}$ & $\mathrm{P}$ \\
\hline $80.31 \pm 0.12$ & $14.10 \pm 0.32$ & $6.19 \pm 0.31$ & $<2.00$ & & 50.2 & 12.3 & 30.1 & 0.6 \\
\hline
\end{tabular}

addition to carbohydrates (48 to $80 \%$ ), several organic substituents such as protein ( 1 to $42 \%$ ), lipids (2 to $8.7 \%$ ), nucleic acids $(0.01$ to $10.9 \%)$, and sulfated groups (up to $10 \%$ ) (Conrad et al. 2003; Zhu et al. 2012; Xiao and Zheng 2016). The concentrations of these components differ significantly with strain/species and culture conditions.

\section{FTIR, ${ }^{1} \mathrm{H}$ NMR, and X-ray analyses}

The FTIR and ${ }^{1} \mathrm{H}$ NMR spectra confirm the heteropolymeric nature of the Graesiella sp. EPSs. The IR spectrum (Fig. 2) displayed a broad band between 3500 and $3000 \mathrm{~cm}^{-1}$ attributed mainly to the stretching vibration $(v)$ of $\mathrm{O}-\mathrm{H}$ or $\mathrm{N}-\mathrm{H}$ and a band centered to $2900 \mathrm{~cm}^{-1}$ attributed to the $\mathrm{vC}-\mathrm{H}\left(\mathrm{CH}_{3}\right.$ and $\mathrm{CH}_{2} \mathrm{sp}^{3}$ ) groups, typical from the hydroxyl and alkyl functionality of carbohydrates, respectively.

The ${ }^{1}$ HNMR spectrum of the EPSs (Fig. 3) confirms this observation by the signals found in the region 3.5-4.1 ppm, assigned to cyclic proton of many sugar residues and typical for polysaccharides (Kaplan Can et al. 2019).

The prominent absorption observed at $1640 \mathrm{~cm}^{-1}$ in the FTIR, attributed to the bending vibration $(\delta)$ of $\mathrm{N}-\mathrm{H}$ and the $\checkmark \mathrm{C}-\mathrm{N}$ observed at $1240 \mathrm{~cm}^{-1}$, indicates the existence of amino acids from peptide/proteins in the EPSs isolated from the Graesiella sp. These observations were confirmed by the
${ }^{1} \mathrm{HNMR}$ spectrum from the peak signal at $1.3 \mathrm{ppm}$, assigned to the N-H groups of primary amides and by the alkyl-halide peak observed at $3.1 \mathrm{ppm}$ (Mishra et al. 2011). The peak at 1240 and $1080 \mathrm{~cm}^{-1}$ could be attributed to the $v \mathrm{~S}-\mathrm{O}$ groups and $v \mathrm{C}-\mathrm{O}-\mathrm{S}$. These data confirm the presence of sulfate groups in the EPSs, as reported for other Cyanobacteria and Chlorophyta exopolymers (Zou et al. 2008; Raposo et al. 2014). The peak recorded at $1020 \mathrm{~cm}^{-1}$, attributed to the $v \mathrm{C}-\mathrm{O}$, is characteristic of uronic acids and $o$-acetyl ester linkage bond in carbohydrates (Bramhachari and Dubey 2006). The ${ }^{1}$ HNMR spectrum confirms this observation by the signal presence located at $7.97 \mathrm{ppm}$ assigned to the $o$-acetyl ester groups.

The X-ray diffraction (XRD) patterns of EPSs produced by Graesiella sp. (Fig. 4) exhibit numerous intense diffraction peaks ranged from 10 to $55^{\circ}$ with interplanar spacing (dspacings) ranged from 1 to $5 \AA$. The multitude of peaks with relatively sharp thin characteristics indicates high crystallinelike nature of Graesiella EPSs which justifies high interaction between the different components.

\section{Protein and antioxidant enzymes analysis}

The EPS HPLC chromatogram (Fig. 5) recorded at $246 \mathrm{~nm}$ showed one prominent peak at 9 min retention time and two
Fig. 2 FTIR spectrum of the EPSs extracted from Graesiella sp.

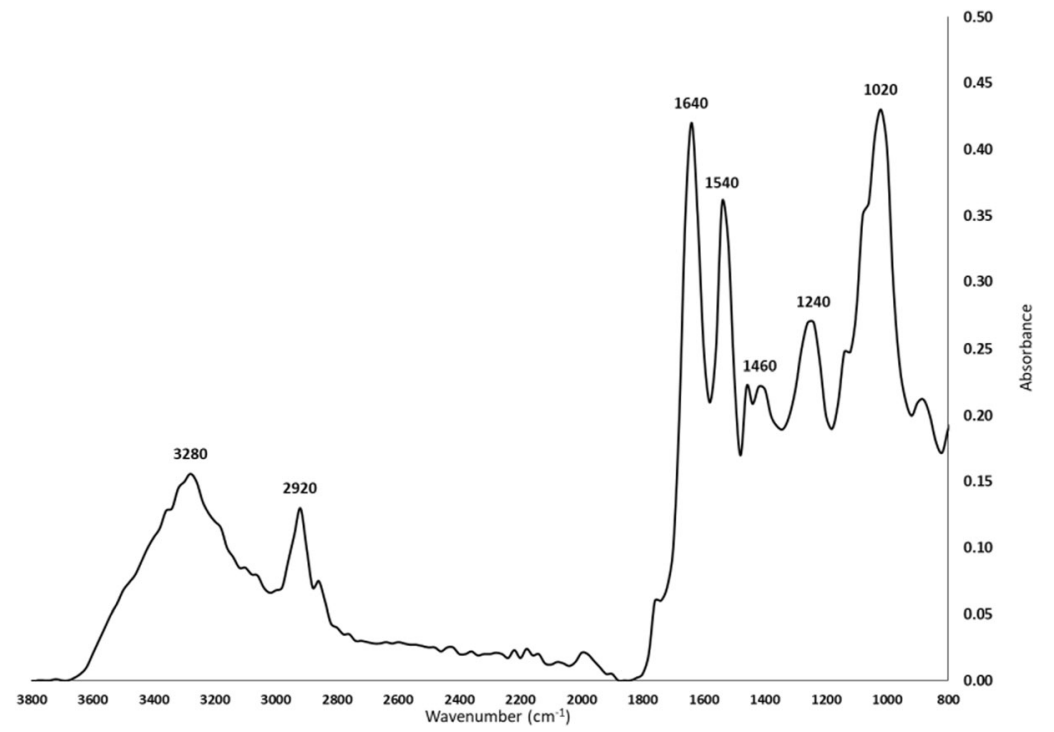


Fig. $3{ }^{1}$ HNMR spectra of the EPSs extracted from Graesiella sp. a Expanded region 3.97$4.07 \mathrm{ppm}$. b Expanded region 2.2-3.4 ppm. Peak at $5 \mathrm{ppm}$ corresponding to the solvent was minimized
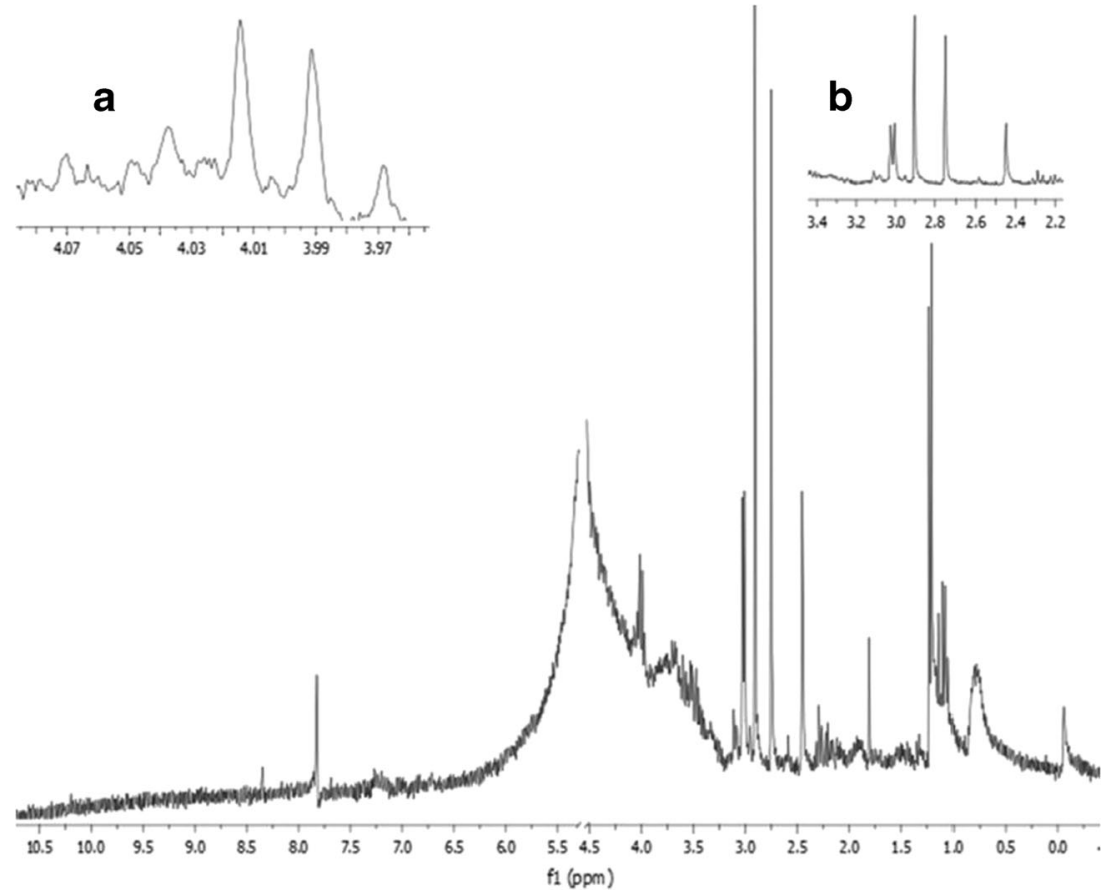

shoulders recorded near 10.5 and $12.5 \mathrm{~min}$ indicating that EPSs were constituted by at least two major groups of compounds. The compounds eluted at 9 min showed a great absorption at 200 and $220 \mathrm{~nm}$, and a smaller absorption at $300 \mathrm{~nm}$. On the other hand, the compounds eluted at 10.5 and $12.5 \mathrm{~min}$ have an absorbance at $200 \mathrm{~nm}$, without the presence of the absorbance at $300 \mathrm{~nm}$. The absorbance at $300 \mathrm{~nm}$ could be attributed to the presence of the hydrosoluble protein mycrosprin amino acids (MAA's) linked to polysaccharides, confirmed by the yellowish color of EPS aqueous solution. This explains the high conductivity signals observed

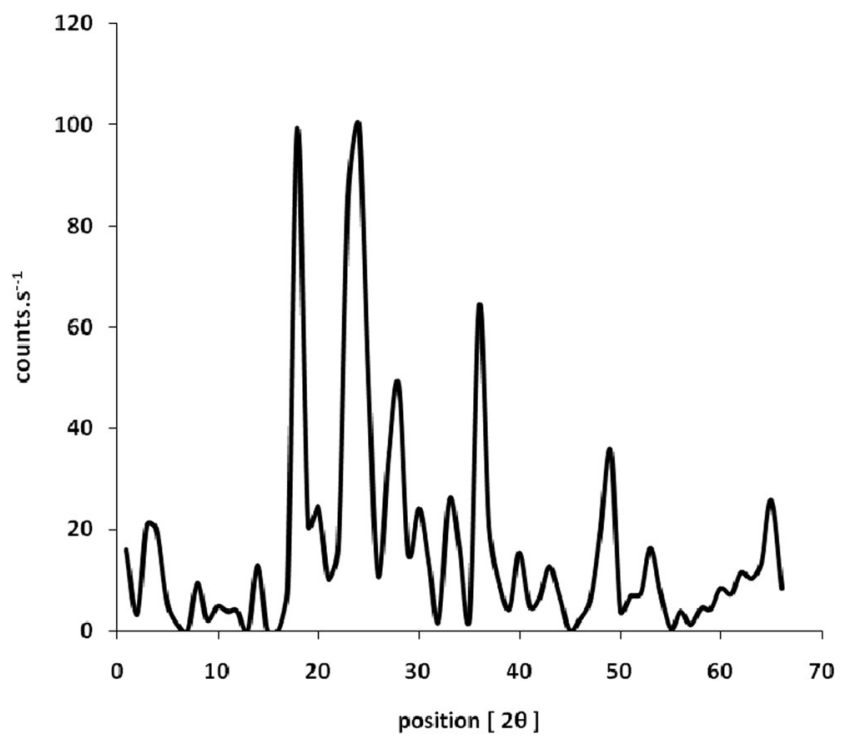

Fig. 4 Representative X-ray diffraction spectrum of EPSs isolated from Graesiella sp. at 9 min which are probably correlated with the presence of charged amino acids.

The EPS protein content was evaluated at $14.10 \%$ of dw (Table 1) which is within the range of proteins reported in some Chlorophyta species, varying from 13 to $50 \%$ (Chiou et al. 2010; Goo et al. 2013). The molecular weight of the EPSs proteins determined by SDS-PAGE analysis showed that EPSs are constituted of ten bands gradually shifting from (25 to $195 \mathrm{kDa}$, Fig. 6), mainly with low molecular weight proteins as shown in some cyanobacteria species (Kawaguchi and Decho 2000).

The bands detected at 35, 69, and $74 \mathrm{kDa}$ could be assigned respectively to the SOD enzyme (Keele et al. 1971), the catalase enzyme (Fu et al. 2014), and the peroxidase enzyme (Nicolas et al. 2003).

The enzymatic investigations of the Graesiella sp. EPSs confirm this hypothesis. Indeed, analysis showed the presence of high activity superoxide dismutase $119.70 \pm 5.6$ (U SOD) and catalase $13.8 \pm 0.14$ (U CAT) and peroxidase ascorbate $0.42 \pm 0.14$ (U APX).

Some extracellular enzymes such as protease (Kellam and Walker 1987), phenol oxidase (Otto and Schlosser 2014), and laccase like enzyme (Otto et al. 2015) have been identified in some Chlorophyta EPSs. Other exoenzymes were also found in several microalga strains (Liu et al. 2016). However, as far we know, the presence of antioxidant enzymes such as SOD, CAT, and APX is not signaled as constituents of microalga/ cyanobacteria or bacterial EPSs. In fact, enzymatic antioxidants are underlined as principal endogenously defense mechanisms adapted by algae to scavenge ROS excess (Liu et al. 2012). SOD is known as the first line of defense against 
Fig. 5 HPLC separation of EPS aqueous extract of Graesiella sp. Detection was recorded at absorbency $246 \mathrm{~nm}$ (full line). Spectrum (200 to $400 \mathrm{~nm}$ ) was registered at retention times $(\mathrm{Rt}$ min) $9,10.5$, and $12.5 \mathrm{~min}$. Conductivity (dotted line) is represented in micro Siemens $(\mu \mathrm{S})$

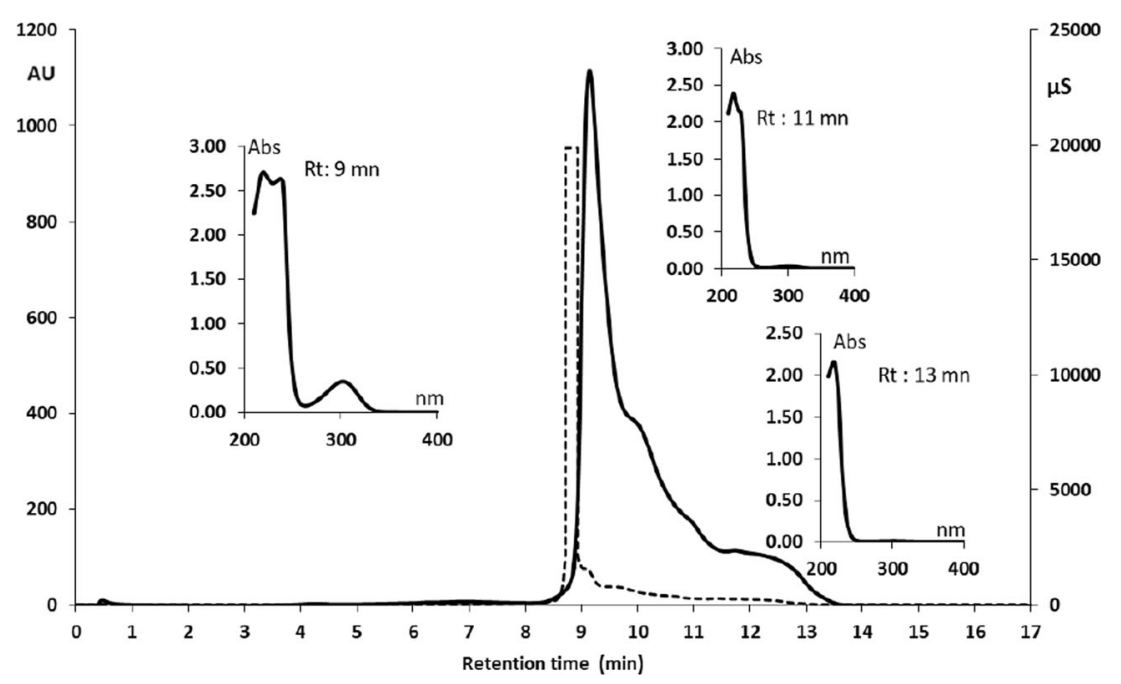

oxygen-derived free radicals (Fridovich 1995), APX as the key enzyme catalyzing the conversion of $\mathrm{H}_{2} \mathrm{O}_{2}$ into $\mathrm{H}_{2} \mathrm{O}$ (Correa-Aragunde et al. 2013), and CAT as the key enzyme present in peroxisomes and mitochondria involved in removal of toxic peroxide (Góth et al. 2004). Maintaining the activity of enzymes in the extracellular matrix suggests a protective microenvironment afforded by EPSs (Hoffman and Decho 1999). Thus, enzymes may be attached to the EPS

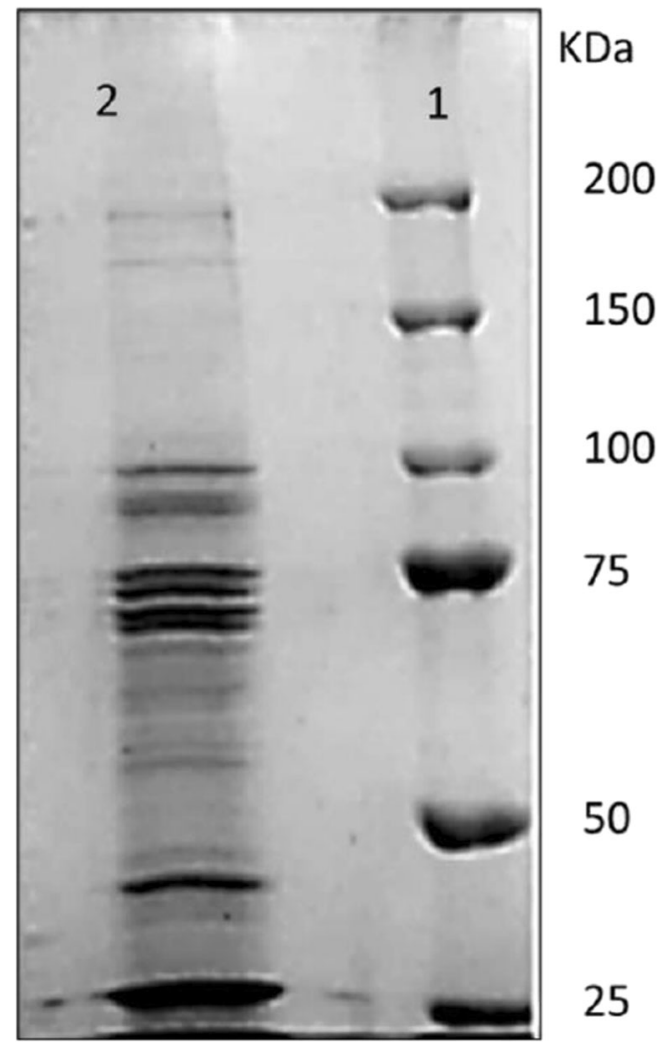

Fig. 6 SDS-PAGE patterns of proteins (lane 2) extracted from the Graesiella sp. EPSs (12\% gel) compared to the molecular weight (10$200 \mathrm{kDa}$ ) of the marker (lane 1) components through ionic and hydrophobic interactions (Gessesse et al. 2003) and/or embedded in the EPS extracellular matrix. Wingender et al. (1999) suggested that the aspect of the matrix architecture is the main responsible that maintain the activity of exoenzymes. In this regard, the high crystalline nature of Graesiella EPSs constitutes a reinforcing grid that enhances the retention of the enzymes in an active state even at high temperatures (Mazeau and Rinaudo 2004). Such findings suppose a potent antioxidant capacity of Graesiella sp. EPSs particularly via directly scavenging $\mathrm{H}_{2} \mathrm{O}_{2}$ and ${ }^{\circ} \mathrm{OH}$ free radicals.

\section{Antioxidant activity}

The antioxidant activities have been attributed to various reactions and mechanisms; three types of stages are encountered in every free-radical reaction: initiation, propagation, and termination (Santos-Sánchez et al. 2019). The antioxidant activity of EPSs in vitro was studied by: (i) total antioxidant capacity (TAC) and $\alpha, \alpha$-diphenyl- $\beta$-picrylhydrazyl free radical scavenging activity (DPPH ${ }^{\circ}$ ); (ii) iron-reducing power; and (iii) hydroxyl radical scavenging activity $\left({ }^{\circ} \mathrm{OH}\right)$ and hydrogen peroxide scavenging activity $\left(\mathrm{H}_{2} \mathrm{O}_{2}\right)$, to evaluate the effects on the initiation, propagation, and termination stages, respectively. TAC and the iron-reducing power of EPSs were expressed as L-ascorbic acid equivalent (equivalents per $\mu \mathrm{gPSs}_{\mathrm{dw}}$ ) by converting absorbance to equivalent activity of L-ascorbic acid based on standard curves. The scavenging ability of EPSs was compared to L-ascorbic by calculating the half inhibitory concentration ( $\mathrm{IC}_{50}$; Table 2 ).

TAC was evaluated by the reduction of $\mathrm{Mo}(\mathrm{VI})$ to $\mathrm{Mo}(\mathrm{V})$ and measured by the absorbance at $695 \mathrm{~nm}$. Both EPSs and Lascorbic TAC were dose dependent (Fig. 7).

The highest TAC value obtained at a concentration of $2000 \mu \mathrm{g}_{\mathrm{dw}} \mathrm{mL}^{-1}$ was slightly lower than that obtained by Lascorbic acid at the same concentration. In terms of L-ascorbic 
Table 2 Radical scavenging ability (\%) of EPSs at different concentrations $\left(\mu \mathrm{g}_{\mathrm{dw}} \mathrm{mL}^{-1}\right)$ and the half inhibitory concentration $\left(\mathrm{IC}_{50} ; \mu \mathrm{g}_{\mathrm{dw}} \mathrm{mL}^{-1}\right)$ for EPSs and L-ascorbic acid

\begin{tabular}{llll}
\hline Concentration $\left(\mu \mathrm{g}_{\mathrm{dw}} \mathrm{mL}^{-1}\right)$ & $\mathrm{DPPH}^{\bullet}$ & ${ }^{\circ}$ & $\mathrm{H}_{2} \mathrm{O}_{2}$ \\
\hline 20 & $20.01 \pm 0.03$ & $18.10 \pm 0.01$ & $50.09 \pm 0.01$ \\
40 & $67.00 \pm 0.01$ & $70.01 \pm 0.08$ & $79.41 \pm 0.02$ \\
50 & $70.04 \pm 0.02$ & $74.20 \pm 0.01$ & $86.11 \pm 0.03$ \\
100 & $82.01 \pm 0.07$ & $73.14 \pm 0.03$ & $86.31 \pm 0.06$ \\
200 & $83.12 \pm 0.03$ & $84.21 \pm 0.02$ & $98.10 \pm 0.04$ \\
500 & $91.08 \pm 0.06$ & $87.14 \pm 0.04$ & $98.20 \pm 0.03$ \\
1000 & $94.51 \pm 0.02$ & $93.21 \pm 0.06$ & $99.19 \pm 0.01$ \\
2000 & $99.27 \pm 0.04$ & $98.12 \pm 0.01$ & $99.22 \pm 0.03$ \\
EPSs $\left(\mathrm{IC}_{50}\right)$ & $40.21 \pm 2.21^{\mathrm{a}}$ & $40.17 \pm 1.18^{\mathrm{a}}$ & $20.11 \pm 1.21^{\mathrm{a}}$ \\
$\mathrm{L}^{\mathrm{a}}$-Ascorbic $\left(\mathrm{IC}_{50}\right)$ & $100.12 \pm 2.12^{\mathrm{b}}$ & $80.22 \pm 3.12^{\mathrm{b}}$ & $40.21 \pm 1.29^{\mathrm{b}}$ \\
\hline
\end{tabular}

$\mathrm{DPPH}^{\bullet}: \alpha, \alpha$-diphenyl- $\beta$-picrylhydrazylfree radical scavenging activity; ${ }^{\circ} \mathrm{OH}$ : hydroxyl radical scavenging activity; $\mathrm{H}_{2} \mathrm{O}_{2}$ : hydrogenperoxide scavenging activity. Values (means $\pm \mathrm{SD}$ of three replicates) not sharing a common letter are significantly different $(p<0.05)$ acid equivalent, EPSs showed a TAC value of $1.4 \mu \mathrm{g}_{\mathrm{dw}}$. Our result highlighted a strong TAC compared to the Chlamydomonas reinhardtii EPSs obtained in laboratory scale under optimal growth condition where the TAC value was $5.6 \mu \mathrm{g}_{\mathrm{dw}}$ (Bafana 2013).

The EPS antioxidant activity was also determined in relation to the $\mathrm{DPPH}^{*}$ (Table 2). The present findings showed that Graesiella EPSs had a perceptible DPPH' activity. The inhibitory activity of EPSs varied from $10.61 \%$ at the concentration of $20 \mu \mathrm{g}_{\mathrm{dw}}$ EPS $\mathrm{mL}^{-1}$ and reached near $99 \%$ at the concentration of $2000 \mu \mathrm{g}_{\mathrm{dw}}$ EPS $\mathrm{mL}^{-1}$. The $\mathrm{IC}_{50}$ of EPSs on $\mathrm{DPPH}^{*}$ was $40 \mu \mathrm{g}_{\mathrm{dw}} \mathrm{mL}^{-1}$ which was strongly lower than that of the standard L-ascorbic, evaluated at $100 \mu \mathrm{g}_{\mathrm{dw}} \mathrm{mL}^{-1}$. In the case

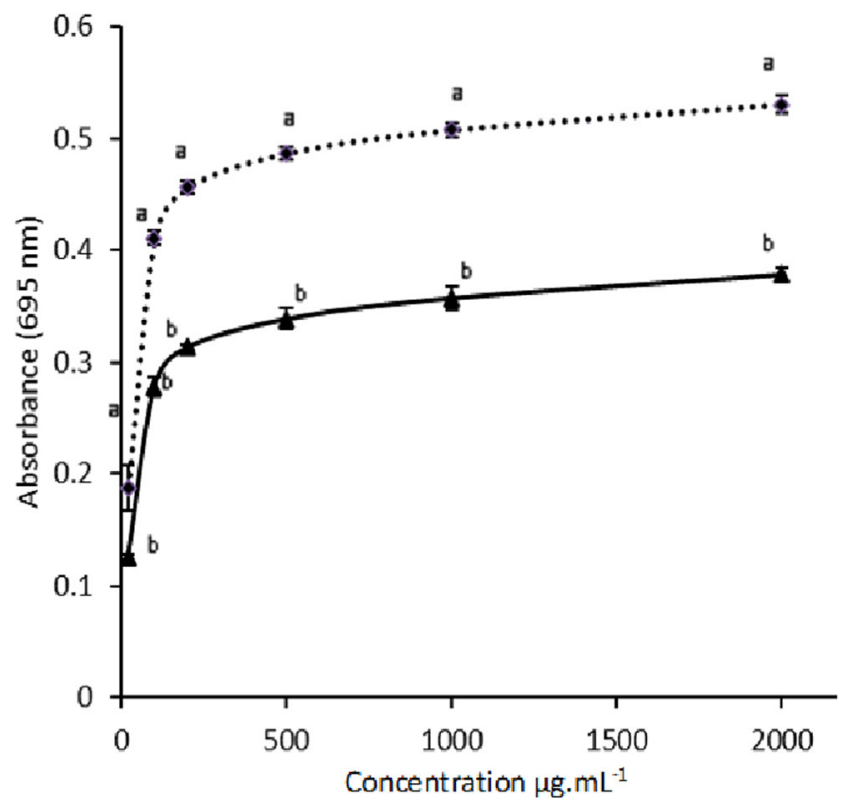

Fig. 7 Total antioxidant activity of EPSs (full line) and L-ascorbic acid (dotted line). Values (mean \pm SD of three replicates) not sharing a common letter are significantly different $(p<0.05)$ of other Chlorophyta species EPSs (Chlorella zofingiensis and Chlorella vulgaris, respectively), the $\mathrm{IC}_{50}$ values were strongly higher reaching 1570 and $1860 \mu \mathrm{g}_{\mathrm{dw}}$ of EPS $\mathrm{mL}^{-1}$ (Zhang et al. 2019a).

The iron-reducing power was studied and compared to Lascorbic acid (Fig. 8). It was clear that the increase of the EPS concentration induces the increase of the absorbance which means the increase of the reducing power. The iron-reducing power of EPSs attends its maximum potential to a concentration of $100 \mu \mathrm{g}_{\mathrm{dw}} \mathrm{mL}^{-1}$. However, at whatever concentration tested, L-ascorbic acid showed higher $(p<0.05)$ reducing power, which suggests weaker ability of the EPSs as an electron donator. In terms of L-ascorbic acid equivalent,

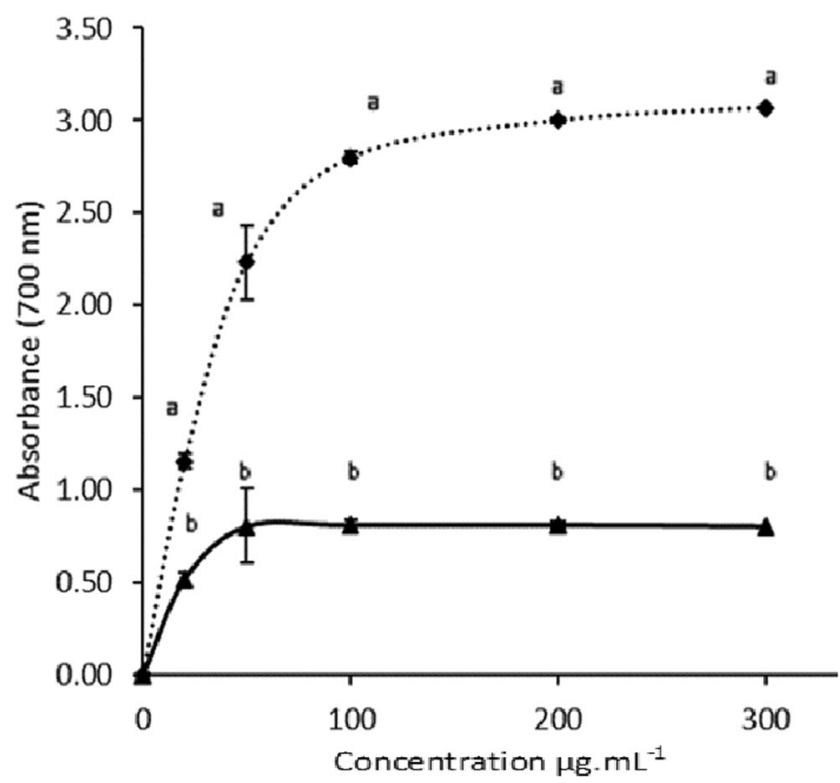

Fig. 8 Iron-reducing activity of EPSs (full line) compared to L-ascorbic acid (dotted line). Values (mean $\pm \mathrm{SD}$ of three replicates) not sharing a common letter are significantly different $(p<0.05)$ 
Graesiella EPS iron-reducing power value was approximated to $3.1 \mu \mathrm{g}_{\mathrm{dw}}$ which shows lower activity than that recorded in the case of Chlamydomonas reinhardtii $\left(2.3 \mu \mathrm{g}_{\mathrm{dw}}\right.$; Bafana 2013)

Reactive oxygen species (ROS) including hydroxyl radical and hydrogen peroxide can react with biomolecules in living cell and caused severe damage, as mutagenesis, carcinogenesis, and cytotoxicity (Phaniendra et al. 2015). Then, EPS scavenging ability on ROS was estimated by the $\mathrm{H}_{2} \mathrm{O}_{2}$ and ${ }^{\circ} \mathrm{OH}$ assays. The results show that EPSs have strong $\mathrm{H}_{2} \mathrm{O}_{2}$ and ${ }^{\circ} \mathrm{OH}$ scavenging ability in a dose-dependent manner. When the concentration of the EPSs was from 20 to $2000 \mu \mathrm{g}_{\mathrm{dw}} \mathrm{mL}^{-1}$, the $\mathrm{H}_{2} \mathrm{O}_{2}$ scavenging ability ranged from 50 to $98 \%$ and the - OH scavenging activity ranged from 20 to $73 \%$. Compared to L-ascorbic, the EPSs exhibits a $\mathrm{H}_{2} \mathrm{O}_{2}$ and ${ }^{\circ} \mathrm{OH}$ inhibitory $\mathrm{IC}_{50}$ values $(40.17 \pm 1.18$ and $20.11 \pm 1.21$, respectively) two time lower. Graesiella EPSs exhibited obvious scavenging activities on hydrogen peroxide $\left(\mathrm{H}_{2} \mathrm{O}_{2}\right)$ than Isochrysis galbana EPSs ( $\mathrm{IC}_{50}, 0.2 \mathrm{mg}_{\mathrm{dw}} \mathrm{mL}^{-1}$; Sun et al. 2014) and comparable to the EPSs isolated from Scenedesmus sp. $\left(\mathrm{IC}_{50}\right.$, $0.38 \mathrm{mg}_{\mathrm{dw}} \mathrm{mL}^{-1}$; Zhang et al. 2019b).

The in vitro results of antioxidant activity analysis indicated that the EPSs from Graesiella sp. possessed powerful scavenging capacity. This ability could be explained by the identified bioactive exoenzymes as SOD, CAT, an APX. Furthermore, reducing power analysis indicated that the EPSs performed the antioxidant activity by multiple mechanisms. The results demonstrate that the Graesiella sp. EPS has great potential to be developed as natural antioxidant or functional food additive.

\section{Conclusion}

The work goal was to propose an operation strategy to enhance the production of extracellular polymeric substances (EPSs) from Graesiella sp. in view of their industrial valorization. The two-step culture process developed and based on the interactive effects of the total medium renewal and heat stress could be easily adopted by the industry. Under these conditions, Graesiella sp. produce large amounts of EPSs rich in polysaccharides with potent antioxidant capacity against ROS free radicals mainly $\mathrm{H} 2 \mathrm{O} 2$ and $\cdot \mathrm{OH}$ ones. This ability could be explained by the identified bioactive exoenzymes as SOD, CAT, and APX. The developed EPS production method has a great impact on the economic viability of microalgal-based industrial exploitation. Graesiella sp. is a promising candidate for large-scale production of EPSs, which are potentially new and safe therapeutic agents that can be incorporated in the food and pharmaceutical industry for the management of oxidative damage-derived disorders.
Funding This work was supported by the Institute of Sciences and Technology of Tunisia and the Tunisian Ministry of Higher Education and Scientific Research. N. Cordeiro and J.L. Gomez Pinchetti thank the support of the European Territorial Cooperation Program PCT-MAC 2014-2020 through the project REBECA-CCT (MAC/1.1.B/269).

\section{References}

Abedin RMA, Taha HM (2008) Antibacterial and antifungal activity of cyanobacteria and green microalgae, evaluation of medium components by Plackett-Burman design for antimicrobial activity of Spirulina platensis. Glob J Biotechnol Biochem 3:22-31

Adjimani JP, Asare P (2015) Antioxidant and free radical scavenging activity of iron chelators. Toxicol Rep 2:721-728

Aebi H (1984) Catalase in vitro. Meth Enzymol 105:121-126

Bae SY, Yim JH, Lee HK, Pyo S (2006) Activation of murine peritoneal macrophages by sulfated exopolysaccharide from marine microalga Gyrodinium impudicum (strain KG03): involvement of the NF-kB and JNK pathway. Int Immunopharmacol 6:473-484

Bafana A (2013) Characterization and optimization of production of exopolysaccharide from Chlamydomonas reinhardtii. Carbohydr Polym 95:746-752

Bischoff HW, Bold HC (1963) Phycological studies. IV Some soil algae from Enchanted Rock and related algal species University of Texas Publication 6318: 1-95

Bkhairia I, Ben Salem R, Nasri R, Jridi M, Ghorbel S, Nasri M (2016) Invitro antioxidant and functional properties of protein hydrolysates from golden grey mullet prepared by commercial, microbial and visceral proteases. J Food Sci Technol 53:2902-2912

Bleeke F, Milas M, Winckelmann D, Klöck G (2015) Optimization of freshwater microalgal biomass harvest using polymeric flocculants. International Aquatic Research 7:235-244

Bramhachari PV, Dubey SK (2006) Isolation and characterization of exopolysaccharide produced by Vibrio harveyi strain VB23. Lett Appl Microbiol 43:571-577

Chandran P, Vysakhi MV, Manju S, Kannan M, Abdul Kader SA, Nair S (2013) In vitro free radical scavenging activity of aqueous and methanolic leaf extracts of Aegle tamilnadensis Abdul Kader (Rutaceae). Int J Pharm Pharmaceut Sci 5:819-823

Chiou YT, Hsieh ML, Yeh HH (2010) Effect of algal extracellular polymer substances on UF membrane fouling. Desalination 250:648652

Conrad A, Suutari MK, Keinänen MM, Cadoret A, Faure P, MansuyHuault L (2003) Fatty acids of lipid fractions in extracellular polymeric substances of activated sludge flocs. J Lipids 38:1093-1105

Córdova-Murueta JH, Garcia-Carreño FL, Navarrete-del-Toro MA (2003) Digestive enzymes present in crustacean feces as a tool for biochemical, physiological, and ecological studies. J Exp Mar Biol Ecol 297:43-56

Correa-Aragunde N, Foresi N, Delledonne M, Lamattina L (2013) Auxin induces redox regulation of ascorbate peroxidase 1 activity by $\mathrm{S}$ nitrosylation/denitrosylation balance resulting in changes of root growth pattern in Arabidopsis. J Exp Bot 64:3339-3349

Delattre C, Pierre G, Laroche C, Michaud P (2016) Production, extraction and characterization of microalgal and cyanobacterial exopolysaccharides. Biotechnol Adv 34:1159-1179

Dubois M, Gilles K, Hamilton J, Rebers P, Smith F (1956) Colorimetric method for determination of sugars and related substances. J Analyt Chem 28:350-356

Ekelhof A, Melkonian M (2017) Microalgal cultivation in porous substrate bioreactor for extracellular polysaccharide production. J Appl Phycol 29:1115-1122 
Enzing C, Ploeg M, Barbosa M, Sijtsma L (2014) Microalgae-based products for the food and feed sector: an outlook for Europe. JRC Sci Policy Rep 19-37

Fernandes HL, Tomme MM, Lupi FM, Fialho AM, Sa-Correia I, Novais JM (1989) Biosynthesis of high concentration of an exopolysaccharide during cultivation of the microalga Botryococcus braunii. Biotechnol Lett 11:433-436

Folch J, Lees MBC, Stanley GHS (1957) A simple method for the isolation and purification of total lipides from animal tissues. J Biol Chem 226:497-509

Fridovich I (1995) Superoxide radical and superoxide dismutases. Annu Rev Biochem 64:97-112

Fu X, Wang W, Hao J, Zhu X, Sun M (2014) Purification and characterization of catalase from marine bacterium Acinetobacter sp. YS0810. Biomed Res Int 409626:1-7

Gaignard C, Macao V, Gardarin C, Rihouey C, Picton L, Michaud P, Laroche C (2018) The red microalga Flintiella sanguinaria as a new exopolysaccharide producer. J Appl Phycol 30:2803-2814

Gantar M, Rowell P, Kerby NW, Sutherland IW (1995) Role of extracellular polysaccharide in the colonization of wheat (Triticum vulgare L.) roots by $\mathrm{N}_{2}$-fixing cyanobacteria. Biol Fertil Soils 19:41-48

Gao L, Pan X, Zhang D, Mu S, Lee DJ, Halik U (2015) Extracellular polymeric substances buffer against the biocidal effect of $\mathrm{H}_{2} \mathrm{O}_{2}$ on the bloom-forming cyanobacterium Microcystis aeruginosa. Water Res 69:51-58

Gessesse A, Dueholm T, Petersen SB, Nielsen PH (2003) Lipase and protease extraction from activated sludge. Water Res 37:3652-3657

Gioti EM, Fiamegos YC, Skalkos DC, Stalikas CD (2007) Improved method for the in vitro assessment of antioxidant activity of plant extracts by headspace solid-phase microextraction and gas chromatography-electron capture detection. J Chromatogr A 1152: 150-155

Goo BG, Baek G, Choi DJ, Park YI, Synytsya A, Bleha R, Seong DH, Lee CG, Park JK (2013) Characterization of a renewable extracellular polysaccharide from defatted microalgae Dunaliella tertiolecta. Bioresour Technol 129:343-350

Góth L, Rass P, Páy A (2004) Catalase enzyme mutations and their association with diseases. Molec Diagnos Ther 8:141-149

Gülçin İ (2006) Antioxidant and antiradical activities of 1-carnitine. Life Sci 78:803-811

Guzmán S, Gato A, Lamela M, Freire-Garabal M, Calleja JM (2003) Anti-inflammatory and immunomodulatory activities of polysaccharide from Chlorella stigmatophora and Phaeodactylum tricornutum: anti-inflammatory and immunodulatory activities. Phytother Res 17:665-670

Haki GD, Rakshit SK (2003) Developments in industrially important thermostable enzymes. Bioresour Technol 89:17-34

Halaj M, Chvalova B, Cepak V, Lukavsk YJ, Capek P (2018) Searching for microalgal species producing extracellular biopolymers. Chem Pap 72:2673-2678

Han P, Sun Y, Wu X, Yuan Y, Dai Y, Jia S (2014) Emulsifying, flocculating, and physicochemical properties of exopolysaccharide produced by cyanobacterium Nostoc flagelliforme. Appl Biochem Biotechnol 172:36-49

Hoffman M, Decho AW (1999) Extracellular enzymes within microbial biofilms and the role of the extracellular polymer matrix. In: Wingender J, Neu TR, Flemming HC (eds) Microbial extracellular polymeric substances. Springer, Berlin, pp 217-230

Hosseini A, Shariati M (2006) Pilot culture of three strains of Dunaliella salina for $\beta$-carotene production in open ponds in the center region of Iran. World J Microbiol Biotechnol 22:1003-1006

Hu C, Völler G, Süßmuth R, Dittmann E, Kehr JC (2015) Functional assessment of mycosporine-like amino acids in Microcystis aeruginosa strain PCC 7806: role of mycosporic acids in M. aeruginosa. Env Microbiol 17:1548-1559
Huheihel M, Ishanu V, Jacov T, Arad S (2002) Activity of Porphyridium sp. polysaccharide against herpes simplex viruses in vitro and in vivo. J Biochem Biophys Meth 50:189-200

Kaplan Can H, Gurbuz F, Odabaşı M (2019) Partial characterization of cyanobacterial extracellular polymeric substances for aquatic ecosystems. Aquat Ecol 53:431-440

Kawaguchi T, Decho AW (2000) Biochemical characterization of cyanobacterial extracellular polymers (EPS) from modern marine stromatolites (Bahamas). Prep Biochem Biotechnol 30:321-330

Keele B, McCord J, Fridovich I (1971) Further characterization of bovine superoxide dismutase and the isolation from bovine heart. J Biol Chem 246:2875-2880

Kellam SJ, Walker JM (1987) An extracellular protease from the alga Chlorella sphaerkii. Biochem Soc Trans 15:520-521

Kumar D, Kvíderová J, Kaštánek P, Lukavský J (2017) The green alga Dictyosphaerium chlorelloides biomass and polysaccharides production determined using cultivation in crossed gradients of temperature and light. Eng Life Sci 17:1030-1038

Lama L, Nicolaus B, Calandrelli V, Manca MC, Romano I, Gambacorta A (1996) Effect of growth conditions on endo- and exopolymer biosynthesis in Anabaena cylindrica 10 C. Phytochemistry 42: 655-659

Laemmli UK (1970) Cleavage of structural proteins during proteins during the assembly of the head of bacteriophage T4. Nature 227:680 685

Li HB, Cheng KW, Wong CC, Fan KW, Chen F, Jiang Y (2007) Evaluation of antioxidant capacity and total phenolic content of different fractions of selected microalgae. Food Chem 102:771-776

Li JY, Jin MM, Meng J, Gao SM, Lu RR (2013) Exopolysaccharide from Lactobacillus planterum LP6: antioxidation and the effect on oxidative stress. Carbohydr Polym 98:1147-1152

Lin R, Liu H, Wu S, Pang L, Jia M, Fan K, Jia S, Jia L (2012) Production and in vitro antioxidant activity of exopolysaccharide by a mutant, Cordyceps militaris SU5-08. Int J Biol Macromol 51:153-157

Liu Y, Guan Y, Gao B, Yue Q (2012) Antioxidant responses and degradation of two antibiotic contaminants in Microcystis aeruginosa. Ecotoxicol Environ Safety 86:23-30

Liu L, Pohnert G, Wei D (2016) Extracellular metabolites from industrial microalgae and their biotechnological potential. Mar Drugs 14:10 190

Lowry OH, Rosebrough NJ, Farr AL, Randall RJ (1951) Protein measurement with the Folin phenol reagent. J Biol Chem 193:265-275

Lupi FM, Fernandes HML, Sá-Correia I, Novais JM (1991) Temperature profiles of cellular growth and exopolysaccharide synthesis by Botryococus braunii Kütz. UC 58. J Appl Phycol 3:35-42

Mazeau K, Rinaudo M (2004) The prediction of the characteristics of some polysaccharides from molecular modeling. Comparison with effective behavior. Food Hydrocoll 18:885-898

Mehta VB, Vaidya BS (1978) Cellular and extracellular polysaccharides of the blue-green alga Nostoc. J Exp Bot 29:1423-1430

Mezhoud N, Zili F, Bouzidi N, Helaoui F, Ammar J, Ouada HB (2014) The effects of temperature and light intensity on growth, reproduction and EPS synthesis of a thermophilic strain related to the genus Graesiella. Bioprocess Biosyst Eng 37:2271-2280

Mishra A, Kavita K, Jha B (2011) Characterization of extracellular polymeric substances produced by micro-algae Dunaliella salina. Carbohydr Polym 83:852-857

Nicolas J, Billaud C, Philippon J, Rouet-Mayer MA (2003) Browing/ enzymatic - biochemical aspects. In: Caballero B (ed) Encyclopedia of food sciences and nutrition, 2nd edn. Academic Press, Oxford, pp. 678-686

Orčić DZ, Mimica-Dukić NM, Francišković MM, PetrovićSS JED (2011) Antioxidant activity relationship of phenolic compounds in Hypericum perforatum L. Chem Central J 5:1-34 
Otto B, Schlosser D (2014) First laccase in green algae: purification and characterization of an extracellular phenol oxidase from Tetracystis aeria. Planta 240:1225-1236

Otto B, Beuchel C, Liers C, Reisser W, Harms H, Schlosser D (2015) Laccase-like enzyme activities from chlorophycean green algae with potential for bioconversion of phenolic pollutants. FEMS Microbiol Lett 362:11

Phaniendra A, Jestadi DB, Periyasamy L (2015) Free radicals: properties, sources, targets, and their implication in various diseases. Indian J Clin Biochem 30:11-26

Prieto P, Pineda M, Aguilar M (1999) Spectrophotometric quantitation of antioxidant capacity through the formation of a phosphomolybdenum complex: specific application to the determination of vitamin E. Anal Biochem 269:337-341

Raposo MFdeJ, de Morais AMMB, de Morais RMSC (2014) Influence of sulphate on the composition and antibacterial and antiviral properties of the exopolysaccharide from Porphyridium cruentum. Life Sci 101:56-63

Rossi F, De Philippis R (2016) Exocellular polysaccharides in microalgae and cyanobacteria: chemical features, role and enzymes and genes involved in their biosynthesis. In: Borowitzka MA, Beardall J, Raven JA (eds) The physiology of microalgae. Springer, Dordrecht, pp 565-590

Ruch RJ, Cheng S, Klaunig JE (1989) Prevention of cytotoxicity and inhibition of intercellular communication by antioxidant catechins isolated from Chinese green tea. Carcinogenesis 10:1003-1008

Santos-Sánchez NF, Salas-Coronado R, Villanueva-Cañongo C, Hernández-Carlos B (2019) Shikimic acid pathway in biosynthesis of phenolic compounds. In: Soto-Hernández M, Garcia-Mateos R, Palma-Tenago M (eds) Plant physiological aspects of phenolic compounds, 2nd edition. IntechOpen, London, pp. 1-28

Shimada K, Fujikawa K, Yahara K, Nakamura T (1992) Auto oxidative properties of xanthan on the autoxidation of soybean oil in cyclodextrin emulsion. J Ag Food Chem 40:945-948

Simonetti E, Alba E, Montes MJ, Delibes Á, López-Braña I (2010) Analysis of ascorbate peroxidase genes expressed in resistant and susceptible wheat lines infected by the cereal cyst nematode, Heteroderaavenae. Plant Cell Rep 29:1169-1178

Soanen N, Da Silva E, Gardarin C, Michaud P, Laroche C (2016) Improvement of exopolysaccharide production by Porphyridium marinum. Bioresour Technol 213:231-238

Sun Y, Wang H, Guo G, Pu Y, Yan B (2014) The isolation and antioxidant activity of polysaccharides from the marine microalgae Isochrysis galbana. Carbohydr Polym 113:22-31

Tang KW, Dam HG (1999) Limitation of zooplankton production: beyond stoichiometry. Oikos 84:537-542
Tannin-Spitz T, Bergman M, van-Moppes D, Grossman S, (Malis) Arad S (2005) Antioxidant activity of the polysaccharide of the red microalga Porphyridium sp. J Appl Phycol 17:215-222

Valko M, Leibfritz D, Moncol J, Cronin MTD, Mazur M, Telser J (2007) Free radicals and antioxidants in normal physiological functions and human disease. Int J Biochem Cell Biol 39:44-84

Varshney P, Mikulic P, Vonshak A, Beardall J, Wangikar PP (2015) Extremophilic micro-algae and their potential contribution in biotechnology. Bioresour Technol 184:363-372

Vigani M, Parisi C, Rodríguez-Cerezo E, Barbosa MJ, Sijtsma L, Ploeg M, Enzing C (2015) Food and feed products from micro-algae: Market opportunities and challenges for the EU. Trends Food Sci Technol 42:81-92

Wingender J, Neu TR, Flemming HC (1999) What are bacterial extracellular polymeric substances? In: Wingender J, Neu TR, Flemming HC (eds) Microbial Extracellular Polymeric Substances. Springer, Berlin, pp 1-19

Xiao R, Zheng Y (2016) Overview of microalgal extracellular polymeric substances (EPS) and their applications. Biotechnol Adv 34:12251244

Yim JH, Kim SJ, Ahn SH, Lee CK, Rhie KT, Lee HK (2004) Antiviral effects of sulfated exopolysaccharide from the marine microalga Gyrodinium impudicum strain KG03. Mar Biotechnol 6:17-25

Zhang J, Liu L, Chen F (2019a) Production and characterization of exopolysaccharides from Chlorella zofingiensis and Chlorella vulgaris with anti-colorectal cancer activity. Int J Biol Macromolec 134:976-983

Zhang J, Liu L, Ren Y, Chen F (2019b) Characterization of exopolysaccharides produced by microalgae with antitumor activity on human colon cancer cells. Int J Biol Macromolec 128:761-767

Zhu C, Chen C, Zhao L, Zhang Y, Yang J, Song L, Yang S (2012) Bioflocculant produced by Chlamydomonas reinhardti. J Appl Phycol 24:1245-1251

Zili F, Bouzidi N, Ammar J, Zakhama W, Ghoul M, Sayadi S, Ben Ouada H (2017) Mixotrophic cultivation promotes growth, lipid productivity, and PUFA production of a thermophilic Chlorophyta strain related to the genus Graesiella. J Appl Phycol 29:35-43

Zou C, Du Y, Li Y, Yang J, Feng T, Zhang L, Kennedy JF (2008) Preparation of lacquer polysaccharide sulfates and their antioxidant activity in vitro. Carbohydr Polym 73:322-331

Publisher's note Springer Nature remains neutral with regard to jurisdictional claims in published maps and institutional affiliations. 